\title{
Desenvolvimento econômico no Matopiba: os arranjos produtivos locais da soja
}

Economic development in Matopiba: local soy clusters

\author{
Thiago J. Arruda de Oliveira ${ }^{a}$ \\ Stefan H. Dörner ${ }^{b}$ \\ Mirian B. Schneider ${ }^{\mathrm{c}}$
}

\begin{abstract}
Resumo: O artigo identifica no Matopiba (Maranhão, Tocantins, Piauí e Bahia) os arranjos produtivos locais do complexo da soja. Para isso, são utilizadas informações provenientes da Produção Agrícola Municipal, fornecidas pelo Instituto Brasileiro de Geografia e Estatística, e da Relação Anual de Informações Sociais, disponibilizada pelo Ministério da Economia. Detectam-se os agrupamentos por meio do índice de concentração normalizado, calculado para 2006 e 2017. Os resultados mostram que os arranjos produtivos locais se localizam no Oeste baiano, no alto do rio Parnaíba (divisa entre o Maranhão e Piauí) e no Tocantins (ao longo da rodovia BR-153 e da ferrovia Norte-Sul, indo do município de Colinas até a divisa com Goiás) formando um eixo de produção especializada na soja.
\end{abstract}

Palavras-chave: Matopiba; Arranjos Produtivos Locais; Soja; Linkage Effects. Classificação JEL: O18; R110

\begin{abstract}
This paper identifies soy clusters in the Matopiba region in Brazil by using data base of the Agricultural Production of Municipalities and Annual Social Information provided by the Brazilian Institute of Geography and Statistics and the Ministry of Economy. The detection of clusters was obtained by calculating a normalized Concentration Index for 2006 and 2017. Soy clusters are localized in East Bahia, the upper part of Parnaíba river, division between Maranhão and Piauí states, and in Tocantins, precisely along the BR - 135 road and North-South railway, starting from the municipality of Colinas until southbound to the state of Goiás, forming a highly specialized soy production axis.
\end{abstract}

Keywords: Matopiba; Local productive agglomerations; Clusters; Linkage effects.

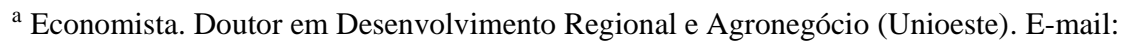
thiago.arruda85@gmail.com

${ }^{\mathrm{b}}$ Administrador. Doutor em Desenvolvimento Regional e Agronegócio (Unioeste). E-mail: stefandoerner@hotmail.com

${ }^{\mathrm{c}}$ Economista. Doutora em História Econômica (Unileon/ESP). E-mail: mirian-braun@ hotmail.com
} 


\section{Introdução}

A disseminação da tecnologia nas atividades agropecuárias, iniciada a partir da década de 1970, transformou o interior do Brasil em um grande produtor de commodities agrícolas (ELIAS, 2015). Esta revolução tecnológica reconfigurou a estrutura espacial do território nacional, criando áreas competitivas vinculadas ao agronegócio globalizado, denominadas de Regiões Produtivas do Agronegócio (RPAs) (OLIVEIRA; RODRIGUES, 2019). Nestas RPAs, presencia-se a atuação de empresas agrícolas e agroindustriais, tradings e corporações concernentes a estas redes - com agentes que proporcionam o desenvolvimento econômico por meio dos linkage effects (NORTH, 1961; HIRSCHMAN, 1977).

O Nordeste brasileiro tornou-se uma RPA por meio da fruticultura irrigada e do cultivo de grãos, especialmente, da soja (OLIVEIRA; RODRIGUES, 2020). A oleaginosa disseminou-se no Cerrado nordestino e nas áreas de transição com a Caatinga e a Mata de Cocais e adentrou no estado do Tocantins. Assim sendo, esta parte do país vem adquirindo características espaciais homogêneas, compondo a delimitação regional intitulada de Maranhão, Tocantins, Piauí e Bahia (Matopiba).

Neste sentido, a soja se estabeleceu como a principal produção do Matopiba. Tratase de uma atividade que repercute na economia regional, seja atraindo unidades que fornecem insumos e bens de capital, ou ramos que atendem à demanda dos trabalhadores (linkage effects). Desse modo, o grão gera efeitos de encadeamento, e esse agrupamento de fatores produtivos em um local resulta na formação de arranjos produtivos locais (APLs) (CROCCO et al., 2006).

Em vista de tais observações, o artigo identifica os arranjos produtivos locais do complexo soja no Matopiba e compara a situação de 2017 com a de 2006. Justifica-se o estudo como forma de observar o nível de especialização e integração vertical da sojicultura nesta parte do país, e como tal atividade afetou a sua configuração espacial.

Para isso, são utilizadas informações provenientes da Produção Agrícola Municipal (PAM), fornecidas pelo Instituto Brasileiro de Geografia e Estatística (IBGE), e da Relação Anual de Informações Sociais (RAIS), disponibilizada pelo Ministério da Economia. A partir daí, detectam-se os agrupamentos por meio do índice de concentração normalizado (ICn).

Este artigo está divido em cinco seções, incluindo esta introdução. Na próxima seção, analisamos o referencial teórico utilizado na compreensão da temática em questão. $\mathrm{Na}$ terceira seção, descrevemos os procedimentos metodológicos usados para trabalhar com os dados coletados da PAM e da RAIS. Na quarta seção, organizamos os resultados e realizamos a discussão acerca deles. Por fim, na quinta seção, explanamos as considerações finais. 


\section{Referencial teórico}

Os arranjos produtivos locais (APLs) são concentrações espaciais de firmas vinculadas a um determinado setor produtivo. Estes agrupamentos possibilitam que empresas pequenas e médias compartilhem informações e superem as barreiras que impedem seu crescimento. Além disso, formam mão de obra especializada e linkage effects, que consistem na atração de demais produtores, fornecedores e consumidores, ampliando o potencial econômico das regiões (HIRSCHMAN, 1977; CROCCO et al, 2006).

Em suma, os APLs que promovem linkage effects transformam a estrutura espacial de uma região, além de promover o seu desenvolvimento econômico. Para isso, a atividade motriz gera efeitos de encadeamento, como: efeitos para frente, que se relacionam às unidades que se estabelecem no entorno da atividade motriz; efeitos para trás, que representam fornecedores de insumos e bens de capital; e demanda final, que abrange as economias abastecedoras do mercado doméstico.

As regiões bem-sucedidas com recursos naturais possuem facilidade em obter linkage effects, desde que o ambiente institucional encoraje o empresariado a explorar estes benefícios. Caso os investimentos sejam insuficientes ou inexiste um mercado consumidor interno que absorva a produção, os ganhos retornam para a atividade motriz do APL, minando qualquer possibilidade de expandir e diversificar a estrutura econômica regional (NORTH, 1961; HIRSCHMAN, 1977).

Assim, os APLs são promotores do desenvolvimento econômico regional, ressaltando-se a importância de identificá-los e, posteriormente, analisá-los do ponto de vista do seu real potencial em atrair novos fatores produtivos (CROCCO et a.l, 2006).

No caso da soja no Matopiba, o cultivo iniciou-se na década de 1970, quando pesquisadores da Empresa Brasileira de Pesquisa Agropecuária (Embrapa), junto com agricultores holandeses, desenvolveram em Balsas, no sul do Maranhão, uma espécie adaptada ao clima do interior do país. À medida que plantadores de grãos do Sul e Sudeste brasileiro aportavam esta espécie no Cerrado, o plantio expandia-se para o interior do Nordeste e avançava também para o Tocantins. O aumento na oferta de crédito rural e a subida dos preços das commodities agrícolas, a partir de 2004, consolidaram a sojicultura nesta RPA (ELIAS; 2015, FREDERICO; BÜHLER, 2015).

Se, por um lado, a soja alterou a estrutura espacial do Matopiba, o seu avanço acarretou também no desmatamento, na pressão social e nos conflitos agrários. Trata-se de uma situação que merece uma análise ponderada. Na prática, a soja possui importância em alimentar os rebanhos bovinos, suínos confinados e as granjas, além de criar inovações tecnológicas no campo (ESPÍNDOLA; CUNHA, 2015).

Neste contexto, existe a possibilidade de os APLs da soja gerarem benefícios no Matopiba, caso os residentes locais usufruam dos ganhos gerados por tal atividade. Contudo, nas regiões sojicultoras do Maranhão, Piauí e Tocantins, nenhuma evidência aponta para a concretização desta relação. Este cenário deve-se à ocupação intensiva no período recente - situação que ainda impossibilita a formação de núcleos urbanos que 
adensariam unidades de saúde e ensino, equipamentos que melhoram o bem-estar dos residentes e formam mão de obra qualificada (OLIVEIRA; DÖRNER, 2015).

Ademais, de acordo com Lemos et al. (2003), o Cerrado nordestino e o Leste tocantinense, até a década de 1980, não tinham base econômica e acesso a rodovias pavimentadas. Diante disso, eram áreas caracterizadas pela atividade de subsistência, ou seja, possuíam baixa densidade populacional e mercado consumidor irrelevante. $\mathrm{Na}$ realidade, o abandono, a pobreza, as patologias sociais e a violência, além da quantidade restrita de postos de trabalho nestas áreas antes do aparecimento da sojicultura, são fatores que dificultaram a formação dos APLs.

Contudo, as RPAs que utilizam o cultivo da soja como base exportadora no Matopiba possuem condições de criar aglomerações produtivas. Este processo reduz a dependência pelo mercado externo, além de contribuir para o fortalecimento das produções domésticas $\mathrm{e}$, consequentemente, ampliar o mercado consumidor interno.

\section{Procedimentos metodológicos}

Num primeiro momento, identificamos os municípios produtores de soja no Matopiba por meio da PAM do IBGE para os anos de 2006 e 2017. A partir destes dados, calculamos as taxas de crescimento da área plantada para cada município e, posteriormente, projetamos em um mapa coroplético, elaborado pelo software Terraview, do Instituto Nacional de Pesquisas Espaciais (INPE), a fim de destacar as áreas com maior crescimento.

Segue a fórmula utilizada para o cálculo das taxas de crescimento do período completo (2017 em relação a 2006):

Taxa de crescimento $=\left(\left(C_{i} / B_{i}\right)^{1 / 10}-1\right) \times 100$

Em que,

$C_{i}=$ Área plantada (em hectares) do respectivo município i em 2017;

$B_{i}=$ Área plantada (em hectares) do respectivo município i em 2006.

Em seguida, a fim de identificar os arranjos produtivos existentes e em formação, calculamos o índice de concentração normalizado (ICn) dos vínculos empregatícios para 2006 e 2017, a partir da RAIS do Ministério da Economia e projetamos os dados em mapas coropléticos. O objetivo era a comparação e a evolução dos arranjos produtivos de soja no período observado.

O ICn é uma ferramenta eficaz para identificar arranjos produtivos de soja no Matopiba. Ele é composto por três subíndices: quociente locacional (QL), HirschmanHerfindahl modificado (HHm) e participação relativa (PR). A sua vantagem relaciona-se com a capacidade de identificar arranjos produtivos locais existentes e aqueles que se encontram em formação (CROCCO et al., 2006).

Em relação ao QL, define-se da seguinte forma: 


$$
Q L=\frac{E_{j}^{i}}{E_{j}} / \frac{E_{B R}^{i}}{E_{B R}}
$$

Em que,

$E_{j}^{i} \quad=$ Emprego da atividade i na região $\mathrm{j}$;

$E_{j} \quad=$ Emprego total na região $\mathrm{j}$;

$E_{B R}^{i} \quad=$ Emprego da atividade i no Brasil;

$E_{B R} \quad=$ Emprego total no Brasil.

Este índice identifica as especializações produtivas de uma região em comparação com uma região de referência. Um QL abaixo de 1 significa que não há diferenciação produtiva, um QL acima de 1 indica apenas que existe diferenciação produtiva. Somente um valor próximo a 4, aponta área especializada.

Outro aspecto considerado é o tamanho da região de análise. Nas pequenas delimitações geográficas existe a possibilidade da sobrevalorização de certa atividade quando o emprego deste setor no local analisado é muito pequeno e a estrutura produtiva pouco ou não diversificada. Ao mesmo tempo, o QL pode subvalorizar certos setores em regiões com estrutura bastante diversificada (CROCCO et al., 2006).

O segundo índice empregado no cálculo do ICn é o Hirschman-Herfindahl modificado (HHm):

$$
H H m=\left(\frac{E_{j}^{i}}{E_{B R}^{i}}\right)-\left(\frac{E_{j}}{E_{B R}}\right)
$$

O índice HHm, ao considerar a importância real da respectiva atividade econômica na estrutura produtiva local, serve para amenizar as possíveis sub ou sobrevalorizações ocasionadas pelo QL (CROCCO et al., 2006). Um HHm positivo indica certa concentração da atividade econômica analisada.

E, completando, o terceiro subíndice, o índice da participação relativa, pondera o peso da atividade na região analisada em relação ao resto do país conforme a seguinte fórmula (CROCCO et al., 2006):

$$
P R=\frac{E_{j}^{i}}{E_{B R}^{i}}
$$

O PR varia entre 0 e 1 , sendo que valores mais próximos de 1 indicam maior participação da atividade na região pesquisada em relação ao resto do país.

Os três subíndices formam o ICn padronizado, que varia conforme os respectivos pesos de cada, representados pelos $\Theta$ s como segue: 


$$
I C n=\Theta_{1} Q L_{i j}+\Theta_{2} H H m_{i j}+\Theta_{3} P R_{i j}
$$

Depois, realizamos o cálculo do ICn para vínculos empregatícios, visto que o ICn para massa salarial identificou os mesmos arranjos produtivos. Elaboramos uma planilha que recebeu os dados extraídos da RAIS, conforme a Classificação Nacional das Atividades Econômicas (CONCLA) do IBGE. Assim, como atividades particulares do segmento foram selecionadas: 01.15-6 (Cultivo de Soja) e 46.22-2 (Comércio Atacadista de Soja). $\mathrm{Na}$ primeira coluna, foram listados todos os municípios com dados; na segunda, a soma do número de vínculos existentes das duas classes para cada município; na terceira, o número total de vínculos de todas as classes; na quarta, o número total de vínculos para as classes 01.16-6 e 46.22-2 no Brasil; e, na quinta, o número total de todos os vínculos no país.

A sexta, sétima e oitava colunas foram preenchidas com as fórmulas para o cálculo de QL, HHm e PR (equações 2, 3 e 4 anteriormente descritas), respectivamente. E, a nona, décima e décima primeira colunas foram reservadas para o cálculo dos pesos $\Theta$ do $\mathrm{ICn}$, cujo valor completo foi determinado na décima segunda coluna para cada município e conforme a equação 5 .

Os respectivos valores dos índices QL, HHm e PR foram copiados e colados para o SPSS, versão 21 . O cálculo dos pesos foi efetuado através de análise multivariada de componentes principais. Estes valores foram novamente transferidos para a planilha conforme a tabela 1 .

Tabela 1: Matriz de coeficientes ou autovetores da matriz de correlação

\begin{tabular}{c|c|c|c}
\hline \hline $\begin{array}{c}\text { Indicador } \\
\text { Insumo }\end{array}$ & Componente 1 & Componente 2 & Componente 3 \\
\hline QL & $\alpha_{11}$ & $\alpha_{12}$ & $\alpha_{13}$ \\
\hline HHm & $\alpha_{21}$ & $\alpha_{22}$ & $\alpha_{23}$ \\
\hline PR & $\alpha_{31}$ & $\alpha_{32}$ & $\alpha_{33}$ \\
\hline \hline
\end{tabular}

Fonte: Crocco et al. (2003). Adaptada pelos autores.

Desta matriz de autovetores, somaram-se os módulos das primeiras três linhas da primeira coluna $\left(\left|\alpha_{11}\right|+\left|\alpha_{12}\right|+\left|\alpha_{13}\right|\right)$ para a obtenção da soma da primeira coluna $\left(\mathrm{C}_{1}\right)$, repetindo-se este procedimento para as primeiras três linhas da segunda $\left(\left|\alpha_{12}\right|+\left|\alpha_{22}\right|+\left|\alpha_{32}\right|\right)$ e da terceira coluna $\left(\left|\alpha_{13}\right|+\left|\alpha_{23}\right|+\left|\alpha_{33}\right|\right)$ e obtenção das somas $C_{2}$ e $C_{3}$. Em seguida, cada valor da matriz na sua respectiva coluna foi dividido pela soma do total de cada coluna, obtendo uma nova matriz $3 \times 3$ conforme a tabela 2 . 
Tabela 2: Matriz de autovetores recalculados ou participação relativa dos indicadores em cada componente

\begin{tabular}{c|c|c|c}
\hline \hline Indicador & Componente 1 & Componente 2 & Componente 3 \\
\hline QL & $\alpha_{11}^{\prime}=\alpha_{11} / \mathrm{C}_{1}$ & $\alpha_{12}^{\prime}=\alpha_{12} / \mathrm{C}_{2}$ & $\alpha_{13}^{\prime}=\alpha_{13} / \mathrm{C}_{3}$ \\
\hline HHm & $\alpha_{21}^{\prime}=\alpha_{21} / \mathrm{C}_{1}$ & $\alpha_{22}^{\prime}=\alpha_{22} / \mathrm{C}_{2}$ & $\alpha_{23}^{\prime}=\alpha_{23} / \mathrm{C}_{3}$ \\
\hline PR & $\alpha_{31}^{\prime}=\alpha_{31} / \mathrm{C}_{1}$ & $\alpha_{32}^{\prime}=\alpha_{32} / \mathrm{C}_{2}$ & $\alpha_{33}^{\prime}=\alpha_{33} / \mathrm{C}_{3}$ \\
\hline \hline
\end{tabular}

Fonte: Crocco et al. (2003). Adaptada pelos autores.

Os valores $\alpha^{\prime}$ ij da tabela 2 representam o peso que cada variável assume dentro de cada componente.

Tabela 3: Autovalores da matriz de correlação ou variância explicada pelos componentes principais

\begin{tabular}{c|c|c}
\hline \hline Componente & Variância explicada pelo componente & Variância explicada total \\
\hline $\mathbf{1}$ & $\beta_{1}$ & $\beta_{1}$ \\
\hline $\mathbf{2}$ & $\beta_{2}$ & $\beta_{1}+\beta_{2}$ \\
\hline $\mathbf{3}$ & $\beta_{3}$ & $\beta_{1}+\beta_{2}+\beta_{3}(=100 \%)$ \\
\hline \hline
\end{tabular}

Fonte: Crocco et al. (2003). Adaptada pelos autores.

Em relação aos autovalores, estes foram incluídos também na planilha. Os autovalores fornecem a variância dos dados associados a cada componente conforme a tabela 3.

Depois, foram calculados os pesos finais de cada indicador insumo, o resultado da soma dos produtos dos $\alpha_{\mathrm{ij}}$ ' e seus respectivos autovalores $\beta$, como segue:

$$
\begin{aligned}
& \Theta_{1}=\alpha^{\prime}{ }_{11} \beta_{1}+\alpha^{\prime}{ }_{12} \beta_{2}+\alpha^{\prime}{ }_{13} \beta_{3} \\
& \Theta_{2}=\alpha^{\prime}{ }_{21} \beta_{1}+\alpha^{\prime}{ }_{22} \beta_{2}+\alpha^{\prime}{ }_{23} \beta_{3} \\
& \Theta_{3}=\alpha^{\prime}{ }_{31} \beta_{1}+\alpha^{\prime}{ }_{32} \beta_{2}+\alpha^{\prime}{ }_{33} \beta_{3}
\end{aligned}
$$

Em que:

$$
\begin{array}{ll}
\theta_{1} & =\text { peso do } \mathrm{QL} ; \\
\theta_{2} & =\text { peso do } \mathrm{HHm} ; \\
\theta_{3} & =\text { peso do } \mathrm{PR} .
\end{array}
$$


A soma dos subíndices deve ser 1. Estes subíndices foram transferidos para a planilha preenchendo a nona, décima e décima primeira colunas e o cálculo final dos ICns para cada município através da soma dos produtos da planilha, conforme a equação 5 .

Em relação aos ICns calculados, foram aplicados filtros para identificar as aglomerações. O primeiro filtro excluía municípios com um ICn abaixo da média ponderada do Brasil, ou seja, ICn negativo, e o segundo filtro, municípios que não apresentaram pelo menos dez estabelecimentos da atividade sojícola. O segundo critério possui base na própria definição das aglomerações, pois não seria possível falar em aglomerações produtivas locais sem a presença de um mínimo de empresas atuantes no segmento (CROCCO, 2006).

\section{Resultados e discussões}

No Matopiba, conforme a figura 1, o Oeste baiano e a parte alta do rio Parnaíba, divisa dos estados do Maranhão com o Piauí, estão as áreas que concentram a maior quantidade de municípios com mais de 50 mil hectares de soja plantada.

Figura 1: Área plantada de soja (hectares) em 2017

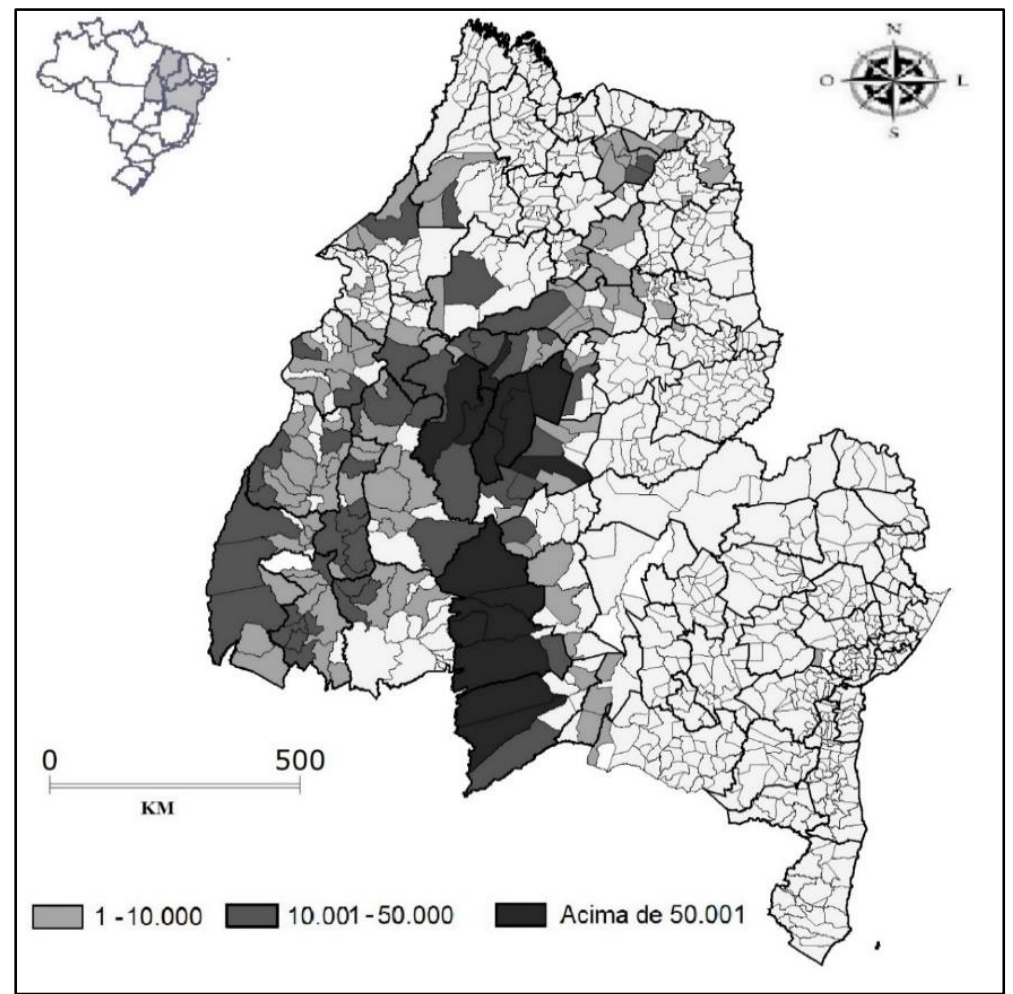

Fonte: PAM (2017). Organizado pelos autores. 
Sob uma topografia plana, clima adequado e intensa luminosidade, a produção de soja no Cerrado nordestino centraliza-se na microrregião de Barreiras, destacando-se Formosa do Rio Preto (figura 1), o líder em área plantada no Matopiba em 2017, com 405.583 ha. A ocupação iniciada no final da década de 1970, a disponibilidade hídrica ofertada pelos afluentes do rio São Francisco e Parnaíba, e a utilização da irrigação do tipo pivô central contribuíram para a expansão da sojicultura no interior do Nordeste.

No Maranhão, em que se desenvolveram os cultivares de soja adaptados ao Cerrado, o município de Balsas apresentou uma área de 187.144 hectares com soja, tornando-se o principal produtor estadual, em 2017. No entorno deste município, Tasso Fragoso e Sambaíba cultivaram também acima de 50 mil hectares de soja. De igual modo, o Cerrado piauiense tem cinco municípios com área plantada acima de 50 mil hectares. Destacam-se, neste contexto, os municípios de Baixa Grande do Ribeiro e Uruçuí com 179.358 e 134.869 hectares de soja, respectivamente.

Por fim, no estado do Tocantins, não registramos municípios com área de soja plantada comparável aos maiores do Nordeste. A tabela 4 sintetiza as informações levantadas para o ano de 2017.

\section{Tabela 4: Área plantada de soja nos municípios do Matopiba acima de 100 mil hectares (2017)}

\begin{tabular}{c|c|c|c}
\hline \hline UF & Município & Microrregião & Área de soja (hectare) \\
\hline BA & Formosa do Rio Preto & Barreiras & 405.583 \\
\hline BA & São Desiderio & Barreiras & 394.016 \\
\hline MA & Balsas & Gerais de Balsas & 187.144 \\
\hline BA & Barreiras & Barreiras & 184.533 \\
\hline PI & Baixa Grande do Ribeiro & Alto Parnaíba Piauiense & 179.358 \\
\hline BA & Luís Eduardo Magalhães & Barreiras & 177.130 \\
\hline BA & Correntina & Santa Maria da Vitória & 172.200 \\
\hline MA & Tasso Fragoso & Gerais de Balsas & 162.675 \\
\hline PI & Uruçuí & Alto Parnaíba Piauiense & 134.869 \\
\hline BA & Riachão das Neves & Barreiras & 120.200 \\
\hline \hline
\end{tabular}

Fonte: PAM (2017). Organizado pelos autores.

De acordo com a tabela 4, dos dez municípios que plantaram acima de $100 \mathrm{mil}$ hectares de soja, cinco estão na microrregião de Barreiras, na Bahia. Juntos, possuíam 1,45 milhão de hectares, correspondendo a quase um terço do total no Matopiba. Os outros municípios que auferiram esses valores produtivos localizavam-se na microrregião Alto Parnaíba Piauiense, Gerais de Balsas e Santa Maria da Vitória. Embora não tenhamos municípios do Tocantins com grandes áreas sojícolas, de acordo com a figura 2, nota-se, 
porém, taxas de crescimento acima de $20 \%$ nesta unidade da Federação. Neste contexto, destacam-se Monte Santo do Tocantins, Muricilândia e Pindorama do Tocantins com 28\% de expansão entre 2006 e 2017.

Em relação ao Maranhão, o município de Sítio Novo, no Sudoeste do estado, apresentou crescimento significativo, assim como o município vizinho de Lajeado Novo. Outra parte do estado que merece atenção é a microrregião Chapadas do Alto Itapecuru e Caxias, localizados próximos da capital Teresina. No que tange ao Piauí, nenhum município desperta alguma consideração.

É interessante observar que os municípios do Oeste baiano que plantaram acima de 100 mil hectares de soja expandiram menos de 10\%, entre 2006 e 2017. Por outro lado, existe uma difusão sojícola direcionando-se para o rio São Francisco. Isto demonstra que a fronteira agrícola do Matopiba está adentrando a Bahia, apesar das seguidas estiagens ao longo dos últimos anos (figura 2).

\section{Figura 2: Taxa de crescimento (\%) da área plantada de soja entre 2006 e} 2017

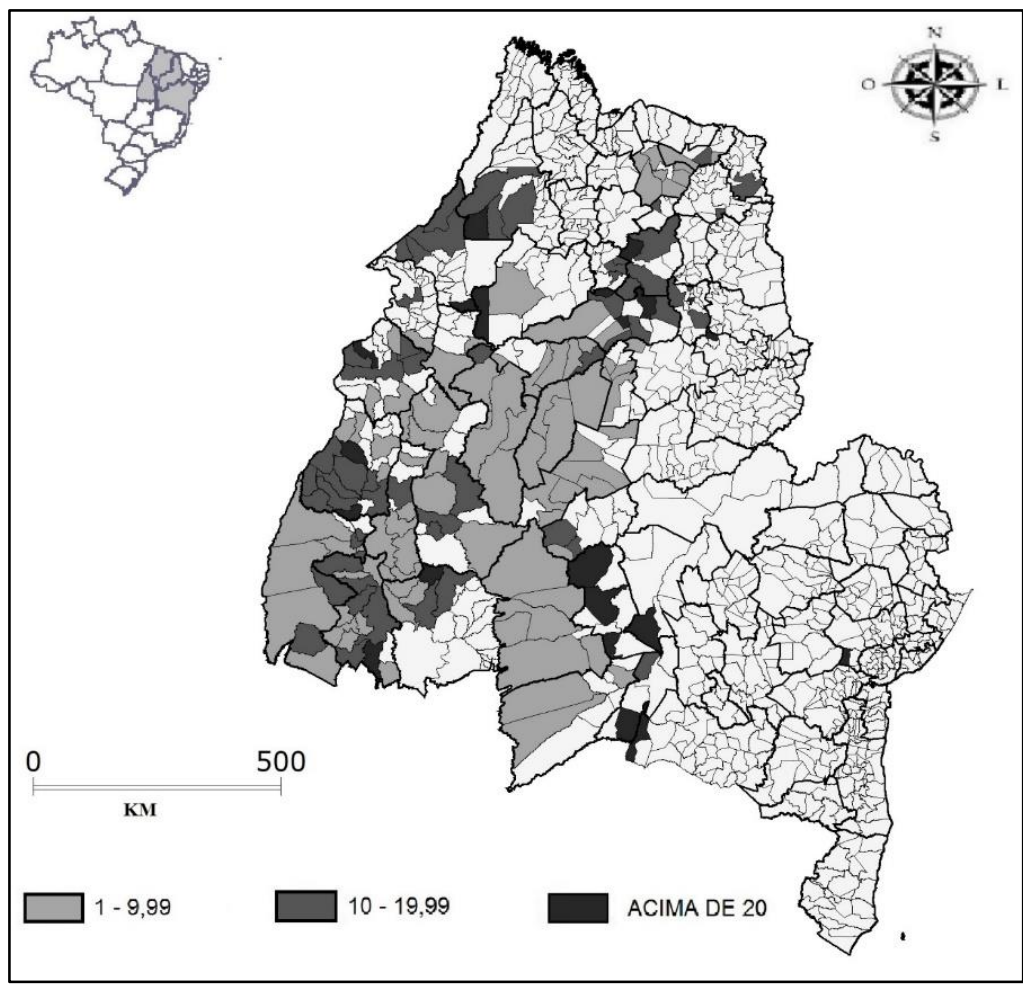

Fonte: PAM (2017). Organizado pelos autores. 
De acordo com a figura 3, no Matopiba, em 2006, foram identificados 22 APLs da soja, sendo: cinco no Maranhão, seis no Piauí, quatro no Tocantins e sete na Bahia.

Os APLs no Maranhão, Piauí e Bahia estavam concentrados em apenas duas microrregiões: no Maranhão, em Gerais de Balsas e Chapada das Mangabeiras; no Piauí, no Alto Parnaíba Piauiense e Alto Médio Gurgueia; e, na Bahia, em Barreiras e Santa Maria da Vitória. Já, no Tocantins, apesar da existência de apenas quatro APLs, estes estavam distribuídos em três microrregiões: Jalapão, Porto Nacional e Miracema do Tocantins.

Com exceção dos municípios de Guaraí, Pedro Afonso e Porto Nacional no Tocantins, todos os outros municípios com APLs formavam um eixo contínuo na direção Norte-Sul, iniciando na parte Sul do Maranhão, Nordeste do Tocantins e Sudoeste do Piauí até o extremo Oeste baiano, quase chegando ao estado de Minas Gerais. Isto não acontece em razão do município de Cocos, na Bahia, não fazer parte dos APLs da soja.

\section{Figura 3: ICn dos arranjos produtivos locais da soja no Matopiba (2006)}

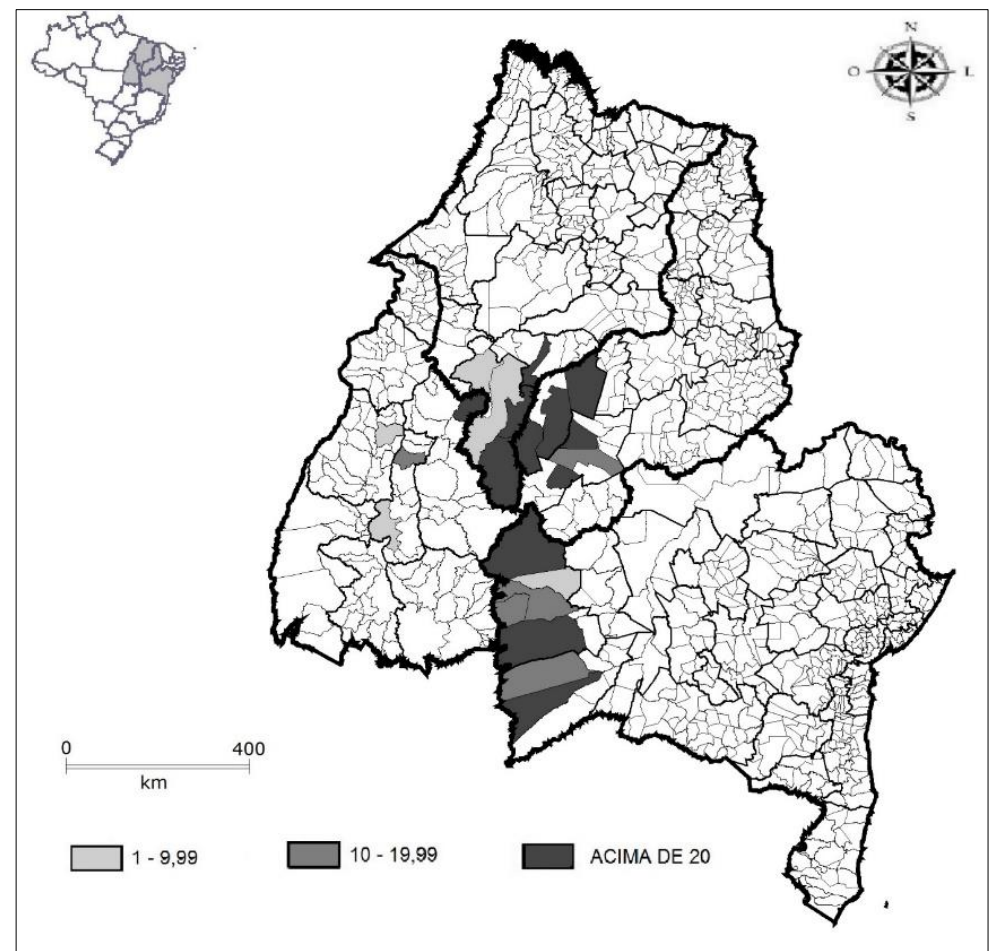

Fonte: resultados da pesquisa. Organizado pelos autores.

Entre os municípios do eixo estão: Campos Lindos no Tocantins, Tasso Fragoso, Alto Parnaíba e Sambaíba no Maranhão; Baixa Grande de Ribeiro, Santa Filomena, Uruçuí, Currais e Monte Alegre do Piauí, áreas próximas do alto do rio Parnaíba; e, Formosa do Rio Preto, Jaborandi e São Desidério no Oeste baiano. Todos esses municípios registraram 
ICns acima de 20 e, portanto, alta concentração. Apenas três municípios deste eixo, Balsas e Riachão, no Maranhão, e Riachão das Neves, na Bahia, contabilizaram ICns de menor concentração e valores abaixo de 10 .

Conforme a figura 4, em 2017, já existiam 54 APLs de soja, 11 no Maranhão, dez no Piauí, 24 no Tocantins e nove na Bahia. O eixo, que existia em 2006, ampliou-se com a agregação de outros municípios, como: Carolina, Fortaleza dos Nogueiras, São Raimundo das Mangabeiras, São Domingos do Azeitão e Loreto, no Maranhão; Ribeiro Gonçalves, Barreiras do Piauí, Santa Filomena, Corrente e Gilbués, no Piauí; Mateiros e Dianópolis, no Tocantins; e, Baianópolis e Cocos, na Bahia.

\section{Figura 4: ICn dos arranjos produtivos locais da soja no Matopiba (2017)}

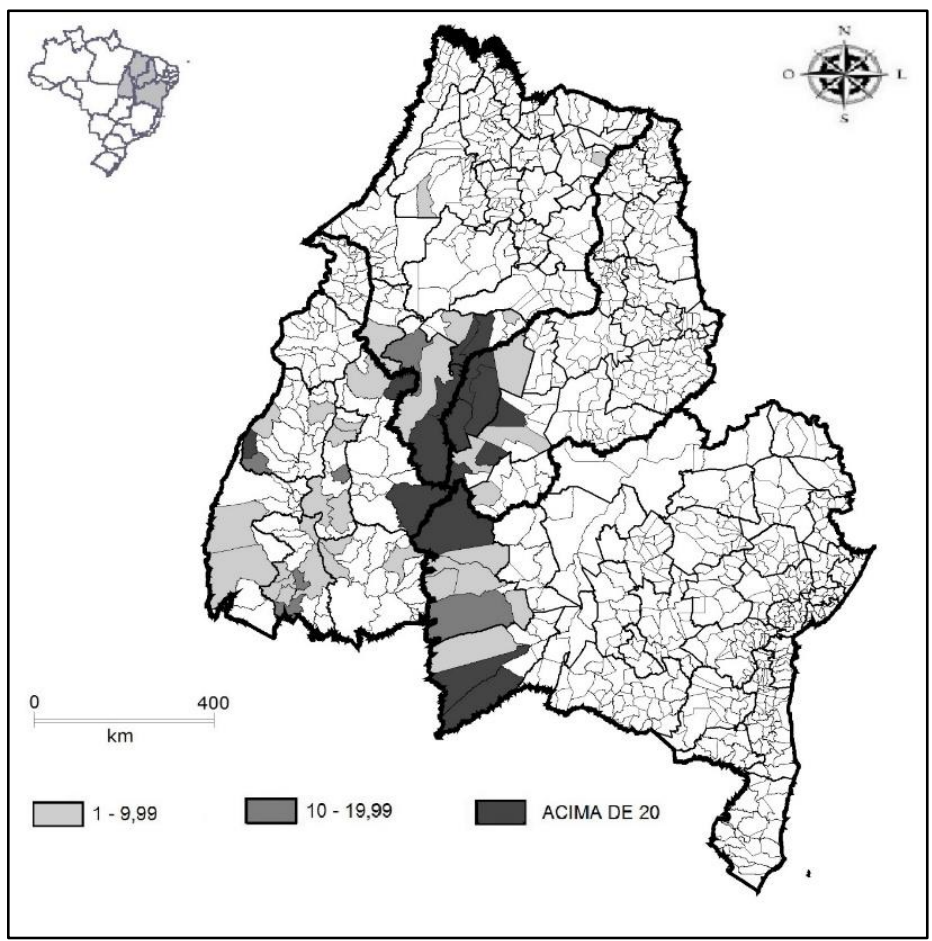

Fonte: resultados da pesquisa. Organizado pelos autores.

Um segundo eixo se formou no centro e Sul do Tocantins, precisamente ao longo da BR-153 e nas proximidades do rio Araguaia, na divisa com o Pará. Como a expansão no estado é recente, é possível a formação de mais APLs nos próximos anos, desencadeados pelo enorme potencial de terras propícias à agricultura e, ainda, por razões logísticas, em especial, devido a efetivação da ferrovia Norte-Sul. A sua conexão com a estrada ferroviária de Carajás, no Maranhão, viabilizou a produção e a exportação de soja via 
Terminal de Grãos do Maranhão (TEGRAM) e o da Ponta da Madeira em São Luís, com capacidade de exportação de até 15 milhões de toneladas até 2025.

Na tabela 5, visualizamos um grande salto na quantidade dos APLs no Matopiba, entre 2006 e 2017, principalmente, devido ao crescimento no Tocantins, cujo número saltou de quatro para 24 e, no Maranhão, que aumentou de cinco para 11. Na Bahia o crescimento foi mais moderado, se compararmos com as outras unidades da Federação. Por outro lado, o Piauí não apresentou uma expansão relevante.

Tabela 5: Quantidade de municípios com APLs da soja no MATOPIBA em 2006 e 2017

\begin{tabular}{c|c|c}
\hline \hline Unidade da Federação & $\mathbf{2 0 0 6}$ & $\mathbf{2 0 1 7}$ \\
\hline Bahia & 7 & 9 \\
\hline Maranhão & 5 & 11 \\
\hline Piauí & 6 & 10 \\
\hline Tocantins & 4 & 24 \\
\hline Total & 22 & 54 \\
\hline \hline
\end{tabular}

Fonte: resultados da pesquisa. Organizado pelos autores.

\section{Conclusão}

Esta pesquisa identificou os municípios do Matopiba com arranjos produtivos locais vinculados ao complexo da soja. Para isso, utilizou-se o índice de concentração normalizada (ICn) e os dados extraídos da RAIS. Complementou-se a análise com informações provenientes da PAM, disponibilizada pelo IIBGE.

Os procedimentos metodológicos utilizados demonstraram que os APLs do complexo da soja avançaram de forma expressiva no Matopiba. No ano de 2006, concentravam-se no Oeste baiano e no alto do rio Parnaíba, divisa entre o Maranhão e Piauí. Em 2015, já haviam adentrado no Tocantins, precisamente ao longo da rodovia BR-153 e da ferrovia Norte-Sul, indo do município de Colinas até a divisa com Goiás, formando um eixo de produção de grão altamente especializado. Os resultados indicam também que os APLs se direcionaram para o Norte e para o Leste do Tocantins, Oeste e Leste do Maranhão e para o extremo Sul do Piauí. Em relação ao Oeste baiano, esta área já estava no limite da sua ocupação agrícola.

O surgimento de APLs da soja no Matopiba relaciona-se com as pesquisas realizadas pela Embrapa, no Maranhão, durante a década de 1970. A partir deste período, difunde-se o plantio de grãos em áreas isoladas como, o Cerrado nordestino e Leste tocantinense. Com a vinda de capital humano e financeiro, alterou-se a estrutura espacial destas localidades. Neste sentido, os APLs possuem função primordial na continuação deste processo ao criar novas atividades econômicas nos municípios pertencentes a tais RPAs. Para isso, deve-se fortalecer o ambiente institucional para que o mesmo incentive o surgimento de inovações 
tecnológicas a partir dos próprios encadeamentos produtivos. As ferrovias assumem importante função ao aumentar a competitividade dos municípios sojicultores, gerando ganhos que viabilizam linkage effects.

Por outro lado, a lentidão das obras da ferrovia Nova Transnordestina e da ferrovia da Integração Oeste-Leste (FIOL), e a inexistência de equipamentos coletivos que formem mão de obra qualificada impedem o prosseguimento das transformações espaciais. Esta lentidão nas transformações estruturais condiz com o abandono das políticas de desenvolvimento regional, já que, atualmente, o governo federal adotou uma postura liberal, isto é, a maior parte dos investimentos estão à cargo da iniciativa privada. Esta medida só funcionará se ocorrerem entradas maciças de capital estrangeiro no país, e diante de uma pandemia na qual se vivencia atualmente, a tarefa se tornou bastante árdua para os governantes.

Logo, os maiores prejudicados são as regiões que possuem um restrito nível de capital acumulado dentro dos seus domínios, como o Matopiba. Deste modo, sem um plano nacional de desenvolvimento regional, os APLs ficam impossibilitados de expandir, especialmente, o complexo da soja. Ademais, sem uma liderança efetiva por parte do Estado, agravam-se os conflitos agrários e elevam-se os crimes ambientais nas RPAs, razões que travam o seu desenvolvimento econômico.

\section{Referências}

CROCCO, M. A.; GALINARI, R.; SANTOS, F.; LEMOS, M. B.; SIMÕES, R. Metodologia de identificação de arranjos produtivos locais. Texto para discussão n. 191. Belo Horizonte: UFMG/Cedeplar, 2006. . Metodologia de identificação de aglomerações produtivas locais. Nova Economia, Belo Horizonte, 16 (2), p. 211-229, mai./ago. 2006.

ELIAS, D. Reestruturação produtiva da agropecuária e novas regionalizações no Brasil. In: ALVES, V. E. L (org). Modernização e regionalização nos Cerrados do Centro Norte do Brasil: Oeste da Bahia, Sul do Maranhão e do Piauí e Leste de Tocantins. Rio de Janeiro: Consequência Editora, pg. 199-44, 2015.

ESPÍNDOLA, C., CUNHA, R. A dinâmica geoeconômica recente da cadeia produtiva da soja no Brasil e no mundo. GeoTextos, Salvador, vol. 11, n. 1, p.217-238, jul.2015.

FREDERICO, S; BÜHLER, E. A. Capital financeiro e a expansão da fronteira agrícola no Oeste da Bahia. In: ALVES, V. E. L (org). Modernização e regionalização nos Cerrados do Centro Norte do Brasil: Oeste da Bahia, Sul do Maranhão e do Piauí e Leste de Tocantins. Rio de Janeiro: Consequência Editora, pg. 199-226, 2015.

HIRSCHMAN, A. O. Transmissão inter-regional e internacional do crescimento econômico. In: SCHWARTZMAN, J. (Org.). Teoria regional e urbana: textos escolhidos. Belo Horizonte: UFMG, p. 35-52, 1977. 
IBGE. Comissão Nacional de Classificação (CONCLA). Disponível em: https://concla.ibge.gov.br/. Acesso em 21 de novembro de 2018.

IBGE. Pesquisa Agropecuária Municipal (PAM). Disponível em: www.sidra.ibge.br. Acesso em 21 de setembro de 2017.

LEMOS. M. B. DINIZ C.C. GUERRA, L.R. MORO, S. A nova configuração regional brasileira e sua geografia econômica. Estudos Econômicos, São Paulo, v.33, n.4, p.665700, 2003.

NORTH, D. C. Problemas teóricos do crescimento regional. Revista Brasileira de Economia, Rio de Janeiro, n ${ }^{\circ}$, p.25-31, 1961.

OLIVEIRA, T. J. A.; DÖRNER, S. H. Desenvolvimento rural nas regiões sojicultoras do MAPITO. Campo-Território: Revista de Geografia Agrária, Uberlândia, v. 10, n. 20, p. 114-134, jul. 2015.

; RODRIGUES, W. Uma análise espacial da estrutura produtiva no interior do Brasil: os clusters do agronegócio. Rev. Econ. NE, Fortaleza, v. 50, n. 1, p. 153-170, jan./mar., 2019.

áreas irrigadas da Caatinga nordestina. Revista em Agronegócio e Meio Ambiente, Maringá, v.13, n.2, p.525-546, abr./jun, 2020. DOI: 10.17765/2176-

9168.2020v13n2p525-546

RAIS. Relação Anual de Informações Sociais. Disponível em:

http://bi.mte.gov.br/bgcaged/login.php. Acesso em 21 de novembro de 2018. 